\title{
Role of acetazolamide in treatment of patients with menstrual migraine
}

\author{
${ }^{1}$ Güldeniz Çetin, ${ }^{1}$ Aysin Kisabay Ak, ${ }^{2}$ Beyhan Cengiz Özyurt, ${ }^{1}$ Deniz Selçuki \\ ${ }^{1}$ Department of Neurology, ${ }^{2}$ Department of Public Health, Celal Bayar University, Manisa, Turkey
}

\begin{abstract}
Objective: According to the ICHD-3 criteria, menstrual migraine (MM) is divided into two groups: pure menstrual migraine (PMM) and menstrually-related migraine (MRM). The present study aimed to evaluate and compare the severity of headache using a visual analog scale (VAS) and the effect on quality of life using the Headache Impact Test (HIT) and Migraine Disability Assessment (MIDAS) tests before and after 3 months of treatment in using short-term prophylaxis with acetazolamide. Methods: Patients who presented to the headache outpatient clinic of the neurology department with a diagnosis of MM were retrospectively reviewed. Acetazolamide was given at a dosage of $500 \mathrm{mg}$ daily for 5 days starting two days before the predicted onset of the menstrual cycle as a short-term prophylactic treatment. VAS, MIDAS, and HIT assessments were performed before and after treatment. Results: A total of 26 patients with PMM and 26 patients with MRM were identified. After acetazolamide treatment, statistically significant improvement was found in MIDAS, VAS and HIT scores in both groups of patients. The post-treatment MIDAS score was significantly lower in the MRM group, but there was no significant difference in post-treatment VAS and HIT scores between the groups.

Conclusion: Using acetazolamide for short-term prophylaxis in patients with MM leads to decreased severity and frequency of headache and improvement in quality of life. The study is the first in the literature to use acetazolamide for short-term prophylaxis in patients diagnosed with MM.
\end{abstract}

Keywords: menstrual migraine; acetazolamide; short-term prophylaxis; VAS; MIDAS; HIT

\section{INTRODUCTION}

Migraine is a periodic, usually unilateral, throbbing type of headache accompanied by nausea and/or vomiting with onset in childhood or young adulthood. ${ }^{1}$ The prevalence of migraine is highest at ages of 25 to 55 years in men as well as women; it is three times more common in women than in men after the third decade of life. ${ }^{2}$ The reasons for the more common occurrence of migraine in women include the presence of the menstrual cycle (MC) and hormonal changes. According to the International Classification of Headache (ICHD-3) criteria, menstrual migraine $(\mathrm{MM})$ is divided into two groups: pure menstrual migraine (PMM) and menstrually-related migraine (MRM). PMM occurs only during menstrual bleeding, whereas MRM may be seen in any period of the cycle as a consequence of hormonal changes. ${ }^{3}$

MRM is seen in around $7 \%$ of the female population and $13 \%$ of women with migraine, whereas PMM is seen in about $2 \%$ of the female population and $8 \%$ of women with migraine..$^{4-6}$

Decreased estrogen level in the late luteal phase has been shown to be the most important cause in the pathophysiology of MM..$^{7-8}$ In addition, inflammation is triggered as a consequence of decreased levels of magnesium and increased levels of prostaglandins, and migraine headache occurs due to cerebral vasoconstriction..$^{7-8}$

The present study aimed to evaluate and compare the severity of headache using a visual analog scale (VAS) ${ }^{9}$ and effects on quality of life using the Headache Impact Test (HIT) ${ }^{10}$ and Migraine Disability Assessment (MIDAS) ${ }^{11}$ tests before and after 3 months of treatment in both groups of patients using acetazolamide for shortterm prophylaxis of migraine.

\section{METHODS}

Patients diagnosed with $\mathrm{MM}$ are routinely given acetazolamide treatment for short-term prophylaxis in our centre. The patients presenting to the headache outpatient clinic of the Neurology

Address correspondence to: Dr. Aysin Kisabay Ak, Assoc. Prof. Doctor of Neurology, Celal Bayar University, Manisa/Turkey 45000. Tel:+90 536 256 6809 , email: aysinkisabay@ hotmail.com

Date of Submission: 16 May 2021; Date of Acceptance: 21 August 2021

https://doi.org/10.54029/2021 hmm 
Department of the Medical Faculty of Celal Bayar University with headache and diagnosed with MM were retrospectively reviewed after obtaining approval from the Celal Bayar University Medical School Ethics Committee (No.: 85252386-050.04.04, Date: 07.10.2019; Clinical Investigations Ethics Committee).

One hundred and six patients with MM were included in the study after identifying patients with a diagnosis of headache between 2015 and 2020. A total of 54 patients were excluded from the study, 35 because of loss to follow-up (PMM:10, MRM:25) and 19 because of intolerance and noncompliance to the acetazolamide within the first month (PMM:4 MRM:15). The medical data of 52 remaining patients comprising 26 patients with PMM and 26 with MRM was analyzed (Figure 1).

The inclusion criteria were: diagnosis of MM according to ICHD-3 and a regular MC (interval 21-35 days) The exclusion criteria were: patients with chronic migraine according to ICHD-3, tension headache, cluster headache, other primary and secondary headaches; patients with other neurologic diseases and other chronic diseases; use of combined oral contraceptives (COC) or other exogenous hormone therapies; lactation and pregnancy; concurrent use of other short or long-term prophylactic drugs; intermediate to high levels of depression and anxiety based on Beck's Anxiety ${ }^{12}$ and Beck's Depression ${ }^{13}$ tests.

The responses of patients to questions regarding characteristics of their headaches and the contents of their headache diaries were recorded when they attended the outpatient clinic. The headache data elicited included demographic characteristics (age at the time of presentation, age at the time of menstruation, age at the onset of MM, bodymass index [BMI], educational status); features in the medical and family history; presentation, location, triggers and features of the headache; symptoms accompanying the headache; presence/ absence of aura as well as the number of days with headache in a month. HIT-6 and MIDAS test scores, VAS scores, previously used symptomatic and prophylactic medications as well as findings in the neurologic and fundoscopic examination were also obtained.

VAS scores measured from 0 to 10 were collected from the records. The frequency of the headaches was determined from HIT (monthly) MIDAS (three-monthly) scores and headache diaries.

Patients were divided into groups according to body mass index. Those with a BMI of $20-25 \mathrm{~kg} /$ $\mathrm{m}^{2}$ were classified as normal, those with a BMI of $25-30 \mathrm{~kg} / \mathrm{m}^{2}$ as overweight, and those with a BMI of $30 \mathrm{~kg} / \mathrm{m}^{2}$ and above as obese.

To exclude secondary headaches, either cranial computed tomography (CT) or cranial magnetic resonance imaging (MRI) was performed in all subjects. Cranial CT angiography was performed because vascular conditions (i.e., arteriovenous malformation, aneurysm) are possible causes for continuous unilateral headaches.

For short term prophylaxis, acetazolamide was started at a dose of $125 \mathrm{mg}$ twice daily for

106 patients followed with diagnosis of menstrual migraine (MM) between 2015 and 2020 were identified

Number of cases with pure menstrual migraine (PMM):40

Number of cases of menstrual related migraine (MRM):66

52 patients using acetazolamide regularly and attending on the visits were included in the retrospective study: patients with PMM: 26, patients with MRM: 26

Figure 1. Flow chart showing recruitment of study patients 
the first two days of the first menstrual period. Acetazolamide was subsequently given at a dose of $250 \mathrm{mg}$ twice daily (500 mg daily) for 5 days starting two days before the predicted onset of the second and third menstrual periods. Adverse effects were noted. Acetazolamide was given with plenty of water and food, and potassium citrate plus potassium bicarbonate tablets were started in the event of symptoms of paresthesia. Routine biochemistry investigations for renal and hepatic function as well as blood counts were performed.

VAS was used to determine the severity of headache before (month 0) and after (month 3) treatment, and MIDAS and HIT tests were performed to determine the frequency of headaches and their impact on quality of life.

\section{Statistical analyses}

The data were analyzed using the IBM SPSS version 23 program. The normality of the distribution of data was determined using the Shapiro-Wilk test. In comparing the parameters between the groups, the independent twosample t-test was used for data showing a normal distribution, and the Mann-Whitney $\mathrm{U}$ test was used for those not showing a normal distribution. To evaluate changes over time, the paired two-sample t-test and Wilcoxon's test were used for data with and without a normal distribution respectively. Pearson's correlation coefficient was used to examine the correlations among the quantitative variables with a normal distribution, and Spearman's rho correlation coefficient was used for non-parametric data.
Chi-square and Fisher's exact tests were used to compare the categorical variables by groups. The results of the analyses are presented as mean \pm standard deviation (SD) and median (minimum - maximum) for quantitative data and as frequency (percentage) for categoric variables. The significance level was set at $\mathrm{p}<0.05$.

\section{RESULTS}

The neurologic examination, fundoscopic findings and imaging investigations of all patients included in the study were normal.

The age at onset of MM and $\mathrm{MC}$ and age at the time of presentation to the outpatient clinic are summarized in total and groups in Table 1. No significant differences were found between the PMM and MRM groups in age at the time of presentation to the outpatient clinic $(\mathrm{p}=0.273)$ or age at the onset of MM $(\mathrm{p}=0.441)$ and MC $(\mathrm{p}=0.529)$.

No statistically significant relationship was found between age at the onset of MM (years) and frequency of MM (days per month) ( $\mathrm{p}=0,369$ $r=0,127)$ and no relationship was found between age of onset of MM and the severity of headaches $(\mathrm{p}=0,488 \mathrm{r}=0,098)$. (Table 1.)

In regard to BMI, $61.5 \%$ of the patients had normal BMI, $28.8 \%$ were overweight, and $9.7 \%$ were obese. BMI was not associated with significant differences $(\mathrm{p}=0.457)$ in headache type. Concerning the educational level of the patients, most of the patients had a university education (30.8\%) or a Master's degree (28.8\%). Educational levels were not significantly different

Table 1: Educational level and evaluation of the age at the time of onset of MM and MC based on the groups and total number of the patients

\begin{tabular}{|c|c|c|c|c|c|}
\hline & & PMM & MRM & All MM & $\mathbf{p}$ \\
\hline \multicolumn{2}{|c|}{$\begin{array}{l}\text { Age at the time of presen- } \\
\text { tation to the outpatient } \\
\text { clinic (years) }\end{array}$} & $34.7 \pm 7.3(20-44)$ & $32.6 \pm 6.5(23-43)$ & $33.7 \pm 6.9(20-44)$ & 0.273 \\
\hline \multicolumn{2}{|c|}{$\begin{array}{l}\text { Age at the onset of MM } \\
\text { (years) }\end{array}$} & $27.3 \pm 8.8(12-39)$ & $25.6 \pm 6.8(14-39)$ & $26.5 \pm 7.8(12-39)$ & 0.441 \\
\hline \multicolumn{2}{|c|}{$\begin{array}{l}\text { Age at the onset of MC } \\
\text { (years) }\end{array}$} & $13.4 \pm 1.3(11-16)$ & $13.6 \pm 1.4(12-16)$ & $13.5 \pm 1.3(11-16)$ & 0.529 \\
\hline \multirow{5}{*}{ 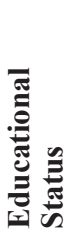 } & Primary school & $5(19.2 \%)$ & $4(15.3 \%)$ & $9(17.3 \%)$ & \multirow{5}{*}{0.480} \\
\hline & Middle School & $0(0 \%)$ & $2(7.7 \%)$ & $2(3.8 \%)$ & \\
\hline & High School & $4(15.4 \%)$ & $6(23.1 \%)$ & $10(19.2 \%)$ & \\
\hline & Undergraduate & $8(30.8 \%)$ & $8(30.8 \%)$ & $16(30.8 \%)$ & \\
\hline & Postgraduate & $9(34.6 \%)$ & $6(23.1 \%)$ & $15(28.8 \%)$ & \\
\hline
\end{tabular}

(Student's T test)

MM, menstrual migraine; MC, menstrual cycle; PMM, pure menstrual migraine; MRM, menstrually-related migraine 
between the MM groups ( $p=0.480)$.

In regard to family history, migraine was present $26.6 \%$ of the PMM group and in $34.2 \%$ of the MRM group $(\mathrm{p}=0.262)$

In the evaluation of the presentation, triggers, features, and associated symptoms of headache, no significant difference was found between MM groups $(\mathrm{p}=0.681, \mathrm{p}=0.321, \mathrm{p}=0.988$, and $\mathrm{p}=0.173$, respectively) (Table 2).

VAS, MIDAS, and HIT scores according to MM type before and after acetazolamide treatment are shown in Table 3.

Table 2: Presentation, features, triggers and associated symptoms of the headached by the groups and total number of the patients

\begin{tabular}{|c|c|c|c|c|c|}
\hline & & PMM & MRM & All MM & $\mathbf{p}$ \\
\hline \multirow{8}{*}{$\begin{array}{l}\text { Presentation of } \\
\text { the headache }\end{array}$} & Prominent during fasting & $13(\% 50)$ & $13(\% 50)$ & $26(\% 50)$ & \multirow[t]{8}{*}{0.681} \\
\hline & Prominent in the nights & $11(\% 42.3)$ & $10(\% 38.5)$ & $21(\% 40.9)$ & \\
\hline & Prominent during exercise & $6(\% 23.1)$ & $10(\% 38.5)$ & $16(\% 30.8)$ & \\
\hline & Prominent with laughing & $3(\% 11.5)$ & $4(\% 15.4)$ & $7(\% 13.5)$ & \\
\hline & Same during daytime & $14(\% 53.8)$ & $10(\% 38.5)$ & $24(\% 46.2)$ & \\
\hline & Prominent with straining & $4(\% 15.4)$ & $7(\% 26.9)$ & $11(\% 21.2)$ & \\
\hline & Prominent in the mornings & $4(\% 15.4)$ & $8(\% 30.8)$ & $12(\% 23.1)$ & \\
\hline & Prominent in the cough & $6(\% 23.1)$ & $6(\% 23.1)$ & $12(\% 23.1)$ & \\
\hline \multirow{8}{*}{$\begin{array}{l}\text { Headache } \\
\text { triggers }\end{array}$} & Stress & $22(\% 84.6)$ & $24(\% 92.3)$ & $46(\% 88.5)$ & \multirow{8}{*}{0.321} \\
\hline & Fatigue & $21(\% 80.8)$ & $25(\% 96.2)$ & $46(\% 88.5)$ & \\
\hline & Seasonal relationship & $9(\% 34.6)$ & $8(\% 30.8)$ & $17(\% 32.7)$ & \\
\hline & Alcohol & $6(\% 23.1)$ & $9(\% 34.6)$ & $15(\% 28.8)$ & \\
\hline & Fasting & $9(\% 34.6)$ & $8(\% 30.8)$ & $17(\% 32.7)$ & \\
\hline & Odor & $12(\% 46.2)$ & $18(\% 69.2)$ & $30(\% 57.7)$ & \\
\hline & Loud noise & $12(\% 46.2)$ & $15(\% 57.7)$ & $27(\% 51.9)$ & \\
\hline & High-intensity light & $10(\% 34.6)$ & $10(\% 42.3)$ & $20(\% 38.5)$ & \\
\hline \multirow{7}{*}{$\begin{array}{l}\text { Features of } \\
\text { headache }\end{array}$} & Penetrating-Jabbing & $6(\% 23.1)$ & $2(\% 7.7)$ & $8(\% 15.4)$ & \multirow{7}{*}{0.988} \\
\hline & In the forehead & $3(\% 11.5)$ & $1(\% 3.8)$ & $4(\% 7.7)$ & \\
\hline & Blunt & $2(\% 7.7)$ & $1(\% 3.8)$ & $3(\% 5.8)$ & \\
\hline & Compressive & $1(\% 3.8)$ & $1(\% 3.8)$ & $2(\% 3.8)$ & \\
\hline & Throbbing & $21(\% 80.8)$ & $22(\% 84.6)$ & $43(\% 82.7)$ & \\
\hline & Lightning & $0(\% 0)$ & $1(\% 3.8)$ & $1(\% 1.9)$ & \\
\hline & Sudden & $3(\% 11.5)$ & $0(\% 0)$ & $3(\% 5.8)$ & \\
\hline \multirow{9}{*}{$\begin{array}{l}\text { Associated } \\
\text { symptoms }\end{array}$} & Nausea & $22(\% 85)$ & $21(\% 85)$ & $43(\% 82)$ & \multirow{9}{*}{0.173} \\
\hline & Vomiting & $7(\% 27)$ & $12(\% 46)$ & $19(\% 36)$ & \\
\hline & Photophobia & $22(\% 85)$ & $23(\% 88)$ & $45(\% 86)$ & \\
\hline & Phonophobia & $22(\% 85)$ & $23(\% 88)$ & $45(\% 86)$ & \\
\hline & Dizziness & $14(\% 54)$ & $20(\% 77)$ & $34(\% 65)$ & \\
\hline & Vertigo & $5(\% 19)$ & $5(\% 19)$ & $10(\% 19)$ & \\
\hline & Allodynia & $12(\% 46)$ & $12(\% 46)$ & $24(\% 46)$ & \\
\hline & Tinnitus & $2(\% 7.7)$ & $6(\% 23)$ & $8(\% 15)$ & \\
\hline & Nausea & $22(\% 85)$ & $21(\% 85)$ & $43(\% 82)$ & \\
\hline
\end{tabular}

(Student's T test)

MM, menstrual migraine; MC, menstrual cycle; PMM, pure menstrual migraine; MRM, menstrually-related migraine 
Table 3: VAS, HIT and MIDAS scores by the groups and total number of the patients before and after treatment

\begin{tabular}{|c|c|c|c|c|}
\hline & & PMM & MRM & All MM \\
\hline \multirow{3}{*}{ VAS } & Baseline VAS & $\begin{array}{l}7.46 \pm 1.17 \\
(4-9)\end{array}$ & $\begin{array}{l}7.81 \pm 1.41 \\
(5-10)\end{array}$ & $\begin{array}{l}7.63 \pm 1.3 \\
(4-10)\end{array}$ \\
\hline & VAS at the end of 3 month & $\begin{array}{l}4.19 \pm 2.37 \\
(0-9)\end{array}$ & $\begin{array}{l}3.46 \pm 2.67 \\
(0-9)\end{array}$ & $\begin{array}{l}3.83 \pm 2.53 \\
(0-9)\end{array}$ \\
\hline & $\mathbf{p}^{*}$ & $<0.001$ & $<0.001$ & $<0.001$ \\
\hline \multirow{3}{*}{ MIDAS } & Baseline MIDAS & $\begin{array}{l}28.2 \pm 13.7 \\
(5-51)\end{array}$ & $\begin{array}{l}32.5 \pm 15.5 \\
(4-62)\end{array}$ & $\begin{array}{l}30.3 \pm 14.6 \\
(4-62)\end{array}$ \\
\hline & MIDAS at the end of 3 month & $\begin{array}{l}13.7 \pm 15.5 \\
(0-67)\end{array}$ & $\begin{array}{l}8.5 \pm 10 \\
(0-44)\end{array}$ & $\begin{array}{l}11.1 \pm 13.1 \\
(0-67)\end{array}$ \\
\hline & $\mathbf{p}^{* *}$ & $<0.001$ & $<0.001$ & $<0.001$ \\
\hline \multirow{3}{*}{ HIT } & Baseline HIT & $\begin{array}{l}58.0 \pm 7.76 \\
(44-75)\end{array}$ & $\begin{array}{l}59.19 \pm 7.24 \\
(38-70)\end{array}$ & $\begin{array}{l}58.6 \pm 7.46 \\
(38-75)\end{array}$ \\
\hline & HIT at the end of 3 month & $\begin{array}{l}46.54 \pm 9.07 \\
(36-68)\end{array}$ & $\begin{array}{l}46.62 \pm 9.92 \\
(36-73)\end{array}$ & $\begin{array}{l}48.08 \pm 9.52 \\
(36-63)\end{array}$ \\
\hline & $\mathbf{p}^{*}$ & $<0.001$ & $<0.001$ & $<0.001$ \\
\hline
\end{tabular}

(*Student's T test **Wilcoxon's test)

MM, menstrual migraine; MC, menstrual cycle; PMM, pure menstrual migraine; MRM, menstrually-related migraine; VAS, visual analog scale; MIDAS, Migraine Disability Assessment; HIT, Headache Impact Test

In regard to baseline VAS scores, there was no significant difference between the groups (p $=0.342$ ). It was remarkable that baseline VAS scores were higher in the MRM group.

Our patients were analysed by headache type with respect to functional status at baseline (month 0 ) and after treatment (month 3). There was a statistically significant difference between the baseline and final mean VAS, MIDAS, and HIT scores in the PMM and MRM groups individually as well as in the entire study group $(p<0.001)$. A decrease in the frequency of the headaches was observed, and an improvement in quality of life occurred in both groups (Table 3 ).

Inter-group differences between mean VAS, MIDAS, and HIT scores at baseline (month 0) and post-treatment (month 3) were evaluated (Table 4). MIDAS scores were significantly different between the PMM and MRM groups $(p=0.033)$ but VAS and HIT scores were not different (VAS: $\mathrm{p}=0.180$, HIT: $\mathrm{p}=0.146)$. It was observed that remarkable improvement occurred post-treatment in all scores, with the most prominent improvement being in the MIDAS score (Table 4).

The frequency of headaches in the PMM and MRM groups before and after treatment (months 0 and 3) is given in Table 5. It was seen that a decrease occurred in the frequency of attacks in both groups, which was greater in the MRM group (Table 5).

Details of HIT and MIDAS scores in the PMM and MRM groups before and after treatment are

Table 4: Differences in average VAS, HIT and MIDAS scores by the groups

\begin{tabular}{|c|c|c|c|c|}
\hline & & PMM & MRM & $\mathbf{p}$ \\
\hline Difference in VAS & $\begin{array}{l}\text { Mean } \pm \text { SD } \\
\text { Mean (Min-Maks.) }\end{array}$ & $\begin{array}{l}-3.27 \pm 2.65 \\
(-8-1)\end{array}$ & $\begin{array}{l}-4.35 \pm 3.05 \\
(-9-3)\end{array}$ & $0.180 *$ \\
\hline Difference in HIT & $\begin{array}{l}\text { Mean } \pm \text { SD } \\
\text { Mean (Min-Maks.) }\end{array}$ & $\begin{array}{l}-8.46 \pm 9.94 \\
(-32-10)\end{array}$ & $\begin{array}{l}-12.58 \pm 10.13 \\
(-29-12)\end{array}$ & $0.146 *$ \\
\hline Difference in MIDAS & $\begin{array}{l}\text { Mean } \pm \text { SD } \\
\text { Mean (Min-Maks.) }\end{array}$ & $\begin{array}{l}-14.42 \pm 12.85 \\
(-38-16)\end{array}$ & $\begin{array}{l}-24 \pm 18.17 \\
(-60-16)\end{array}$ & $0.033 *$ \\
\hline
\end{tabular}

(*Student's T test **Wilcoxon's test)

MM, menstrual migraine; MC, menstrual cycle; PMM, pure menstrual migraine; MRM, menstrually-related migraine; VAS, visual analog scale; MIDAS, Migraine Disability Assessment; HIT, Headache Impact Test 
Table 5: Comparison of attack frequency by the groups before and after treatment

\begin{tabular}{lllll}
\hline $\begin{array}{l}\text { ATTACK } \\
\text { FREQUENCY }\end{array}$ & $\begin{array}{l}\text { PMM Attack } \\
\text { frequency } \\
\text { (number of } \\
\text { days/month) }\end{array}$ & $\begin{array}{l}\text { PMM Attack } \\
\text { frequency } \\
\text { (number of } \\
\text { days/month) }\end{array}$ & $\begin{array}{l}\text { MRM Attack } \\
\text { frequency } \\
\text { (number of } \\
\text { days/month) }\end{array}$ & $\begin{array}{l}\text { MRM Attack } \\
\text { frequency } \\
\text { (number of } \\
\text { days/month) }\end{array}$ \\
\hline & Before Treatment & After Treatment & Before Treatment & After Treatment \\
\hline $0-\leq 2$ & $4(\% 15.4)$ & $7(\% 26.9)$ & $2(\% 7.7)$ & $17(\% 65.5)$ \\
$2-\leq 3$ & $7(\% 26.9)$ & $10(\% 38.5)$ & $1(\% 3.8)$ & $3(\% 11.5)$ \\
$3-\leq 4$ & $9(\% 34.6)$ & $4(\% 15.4)$ & $5(\% 19.2)$ & $0(\% 0)$ \\
$4-\leq 5$ & $4(\% 15.4)$ & $3(\% 11.5)$ & $6(\% 23.1)$ & $3(\% 11.5)$ \\
$>5$ & $2(\% 7.7)$ & $2(\% 7.7)$ & $12(\% 46.2)$ & $3(\% 11.5)$ \\
\hline
\end{tabular}

PMM, pure menstrual migraine; MRM, menstrually-related migraine;

given in Table 6. Improvement occurred in both HIT and MIDAS scores, indicating increased quality of life in both groups, with the difference being more prominent in the MRM group (Table 6).

When adverse effects of acetazolamide were reviewed, it was found that the most common adverse effects of acetazolamide in both the MRM and PMM groups were dizziness and paresthesia ( $60.8 \%, 47.1 \%$ retrospectively). There were no significant difference in adverse events between the groups $(\mathrm{p}=0.486)$. Other symptoms observed included fatigue $(40 \%)$, dry mouth $(33.3 \%)$, nausea $(12 \%)$, polyuria $(19.4 \%)$, anorexia $(19.4 \%)$ and dysgeusia (17.6\%).

\section{DISCUSSION}

Acetazolamide was administered as a short-term prophylactic treatment for MM in this study and was found to decrease severity and frequency of headaches and to improve quality of life.

Some studies have shown that migraine attacks last longer, occur more frequently, and are more severe in patients with MM, especially in those with PMM, than in patients with non-menstrual related migraine. The prevalence of status migrainosus is also higher in patients with MM. ${ }^{14-16}$ By contrast, a study using population-based pain diaries found that there was no difference in the duration of headaches between migraine patients with and without MM. ${ }^{17}$

Prophylaxis of attacks, especially shortterm prophylaxis, has an important role in the treatment of MM. Medications used thus far for short-term prophylaxis include non-steroidal

Table 6: Comparison of HIT and MIDAS scores between the groups before and after treatment

\begin{tabular}{|c|c|c|c|c|c|c|}
\hline & $\begin{array}{l}\text { PMM } \\
(n=26)\end{array}$ & & $\mathbf{p}^{*}$ & $\begin{array}{l}\text { MRM } \\
(n=26)\end{array}$ & & $\mathbf{p}^{*}$ \\
\hline HIT GROUP & Month 0 & Month 3 & \multirow{5}{*}{$\mathbf{0 . 0 3 0}$} & Month 0 & Month 3 & \multirow{5}{*}{0.002} \\
\hline$<49$; Min impact on everyday life & $3(\% 11.5)$ & $13(\% 50)$ & & $2(\% 7.7)$ & $17(\% 65.4)$ & \\
\hline $\begin{array}{l}\text { 50-55; Less impact on everyday } \\
\text { life }\end{array}$ & $4(\% 15.4)$ & $6(\% 23.1)$ & & $5(\% 19.2)$ & $5(\% 19.2)$ & \\
\hline $\begin{array}{l}\text { 56-59; Significant impact on } \\
\text { everyday life }\end{array}$ & $4(\% 15.4)$ & $4(\% 15.4)$ & & $2(\% 7.7)$ & $1(\% 3.8)$ & \\
\hline$>60$; Max impact & $15(\% 58.2)$ & $3(\% 11.5)$ & & $17(\% 65.4)$ & $3(\% 11.5)$ & \\
\hline \multicolumn{7}{|l|}{ MIDAS GROUP } \\
\hline 0-5; No limitation & $2(\% 7.7)$ & $9(\% 34.6)$ & \multirow{5}{*}{0.010} & $1(\% 3.8)$ & $12(\% 46.2)$ & \multirow{5}{*}{$<0.001$} \\
\hline 6-10; Intermediate or infrequent & $1(\% 3.8)$ & $6(\% 23.1)$ & & $0(\% 0)$ & $8(\% 30.8)$ & \\
\hline limitation & & & & & & \\
\hline 11-20; Average limitation & $5(\% 19.2)$ & $6(\% 23.1)$ & & $5(\% 19.2)$ & $3(\% 11.5)$ & \\
\hline 21 and above; severe limitation & $18(\% 69.3)$ & $5(\% 19.2)$ & & $20(\% 77)$ & $3(\% 11.5)$ & \\
\hline
\end{tabular}


anti-inflammatory drugs (NSAID), triptans, ergot derivatives, hormone replacement, magnesium, and indomethacin. ${ }^{18-24}$ The present study investigated the effect of acetazolamide in shortterm prophylaxis.

When the relationship between $\mathrm{MC}$ and cerebrospinal fluid (CSF) flow is examined from a different pathophysiologic perspective, it has been shown that the increased volume and flow rate of CSF in the late luteal phase may trigger headaches following a peak of luteinizing hormone $(\mathrm{LH}) .^{25}$

Decreased volume of CSF and increased volume of the gray matter were found in the menstrual phase during which no significant changes occur in progesterone levels, but when estrogen levels increase significantly in the blood. In the phase following the LH surge during which estrogen level is lowest and progesterone level is highest, increased CSF flow and decreased gray matter volume were found. ${ }^{6}$ Studies have shown that acetazolamide, with its strong vasodilator properties, may reverse the cerebral vasoconstriction which plays a role in the pathophysiology of migraine headaches and decrease intracranial pressure by reducing increased blood flow rate and production of CSF during the luteal phase. ${ }^{26,27}$ It does this by inhibiting carbonic anhydrase after passing the blood-brain barrier, thus producing acidosis ${ }^{28}$ Due to acidosis, cerebral vessels undergo vasodilation, which increases cerebral blood flow. This vasodilating effect of acetazolamide was observed only on constricted arterioles.$^{29}$ It has been shown that no vasodilation occurs in the carotid and vertebral arteries when $250 \mathrm{mg}$ of acetazolamide is given intravenously ${ }^{30}$, but that a higher $500 \mathrm{mg}$ of intravenous acetazolamide is effective..$^{31}$ This change in the cerebral vessels may also occur as a consequence of the direct effect of perivascular $\mathrm{pH}$ and nitric oxide. ${ }^{32}$

Acetazolamide may be given orally and intravenously. Its effect starts in 1 to 1.5 hours and lasts for 8 to 12 hours. ${ }^{33,34}$ It was deemed appropriate to give our patients $500 \mathrm{mg}$ of the drug twice daily based on experimental as well as therapeutic studies.

In the present study, 3 months of acetazolamide was given as short-term prophylaxis for MM for 5 days from two days before the predicted onset of the MC. Keeping adverse effects in mind, it was advised that the drug should be taken at half the target dose twice daily for the first two days of the first menstrual cycle. During acetazolamide use, hepatic and renal function, electrolytes, and hemogram were monitored. The most commonly observed adverse effects in our patients were dizziness and parasthesiae. Potassium citrate plus potassium bicarbonate tablets were given to patients with paresthesia during this period. Despite these measures, 15 patients in the PMM group and four in the MRM group discontinued the acetazolamide treatment because they could not tolerate the drug.

Evaluations were made in light of the tests performed before (month 0 ) and after (month 3) the treatment. At baseline and the post-treatment (month 3) evaluation, a clear improvement occurred in the VAS, MIDAS, and HIT scales individually in each group, as well as in all subjects in general, with the improvement being most prominent on the MIDAS scale. When the pre-treatment VAS values were examined, the headache severity of the cases in the MRM group was observed to be higher, although the difference was not statistically significant. Similarly, in the post-treatment evaluation, the patients in the MRM group had a more significant improvement in the severity of their headaches.

Similarly, it was remarkable that attack frequency was higher in the MRM group than in the PMM group at baseline. When the pre and post-treatment situations were compared, it was seen that frequency of headaches decreased in both groups with the difference being more prominent in the MRM group.

Scoring of the HIT and MIDAS tests were evaluated. The number of patients with a HIT score above 60 and a MIDAS score above 21 before treatment was significantly higher in the MRM group.

It was seen that decrease in both MIDAS and HIT scores post-treatment occurred in both groups, but was more prominent in the MRM group, suggesting that remarkable improvement occurred in quality of life following the decrease in frequency and severity of pain.

Acetazolamide significantly reduced the severity and frequency of headaches occurring during menstruation in both the PMM and MRM groups. The severity of headaches in the patients included in the present study was evaluated in all patients as well as between MM groups. In MRM, however, migraine attacks may occur in any period of the MC and these patients had more frequent, longer, and severe headaches during the $\mathrm{MC}$, due to hormonal changes and other triggers. In the MRM group, giving treatment for attacks of headache (NSAID, triptans) occurring in periods of the cycle other than menstruation sufficed. No additional prophylaxis was needed in either group. 
In literature the overall evaluation of the patients presenting to the headache outpatient clinic, it was seen that number of the patients with MRM was higher than that of patients with PMM. ${ }^{4,5}$ The equal number of patients in both groups in our study occurred by chance due to our inclusion and exclusion criteria as well as the short duration of the retrospective evaluation.

The main limitation of the present study was that it was retrospective. There was no placebo arm. Placebo-controlled, randomized studies with a higher number of patients are needed to more clearly and exactly evaluate the efficacy of the drug.

In conclusion, acetazolamide is effective for short term prophylaxis of MM. The present study is the first to be performed using acetazolamide for this purpose.

\section{DISCLOSURE}

Financial support: None

\section{Conflict of interest: None}

\section{REFERENCES}

1. Rasmussen BK (2001) Epidemiology of headache. Cephalalgia 2001; 21(7) 774-7.

2. Lipton RB, Bigal ME (2005) Migraine: epidemiology, impact, and risk factors for progression. Headache 2005;45(Suppl 1):S3-S13.

3. Headache Classification Committee of the International Headache Society (IHS). The International Classification of Headache Disorders, 3rd edition. Cephalalgia 2018; 38(1): 1-211.

4. Vetvik KG, Macgregor EA, Lundqvist C, Russell MB. Self-reported menstrual migraine in the general population. J Headache Pain 2010;11(2):87-92.

5. Vetvik KG, Macgregor EA, Lundqvist C, Russell MB. Prevalence of menstrual migraine: a population-based study. Cephalalgia 2014; 34(4): 280-8.

6. Marcus DA, Bernstein CD, Sullivan EA, Rudy TE. A prospective comparison between ICHD-II and probability menstrual migraine diagnostic criteria. Headache 2010;50(4):539-50.

7. Benedetto C. Eicosanoids in primary dysmenorrhea, endometriosis and menstrual migraine. Gynecol Endocrinol 1989; 3(1) 71-94.

8. Cupini LM, Matteis M, Troisi E, Calabresi P, Bernardi G, Silvestrini M. Sex-hormone-related events in migrainous females. A clinical comparative study between migraine with aura and migraine without aura. Cephalalgia 1995; 15(2) 140-4.

9. Gould D, Kelly D, Goldstone L, Gammon J. Examining the validity of pressure ulcer risk assessment scales: developing and using illustrated patient simulations to collect the data. J Clin Nurs 2001; 10(5): 697-706.

10. Yalınay Dikmen $\mathrm{P}$, Bozda ğ $\mathrm{M}$, Güneş $\mathrm{M}$, et al.
Reliability and validity of Turkish version of Headache Impact Test (HIT-6) in patients with migraine. Arch Neuropsychiatr 2021; 58. DOI: 10.29399/npa.24956.

11. Ertas M, Siva A, Dalkara T, et al. Validity and reliability of the Turkish Migraine Disability Assessment (MIDAS) questionnaire. Headache 2004; 44(8): 786-93.

12. Beck AT, Epstein N, Brown G, Steer RA. An inventory for measuring clinical anxiety: psychometric properties. J Consult Clin Psychol 1988;56(6) 893-7.

13. Beck AT, Ward CH, Mendelson M, Mock J, Erbaugh J. An inventory for measuring depression. Arch Gen Psychiatr 1961; 4:561-71.

14. Couturier EG, Bomhof MA, Neven AK, van Duijn NP. Menstrual migraine in a representative Dutch population sample: prevalence, disability and treatment. Cephalalgia 2003;23(4):302-8.

15. Vetvik KG, Russell MB. Are menstrual and nonmenstrual migraine attacks different? Curr Pain Headache Rep 2011; 15(5) 339-42.

16. Granella F, Sances G, Allais G, et al. Characteristics of menstrual and nonmenstrual attacks in women with menstrually related migraine referred to headache centres. Cephalalgia 2004; 24(9) 707-16.

17. Stewart WF, Lipton RB, Chee E, Sawyer J, Silberstein $\mathrm{SD}$. Menstrual cycle and headache in a population sample of migraineurs. Neurology 2000; 55(10) 1517-23.

18. Bigal ME, Serrano D, Buse D, Scher A, Stewart WF, Lipton RB. Acute migraine medications and evolution from episodic to chronic migraine: a longitudinal population-based study. Headache 2008; 48(8) 1157 68.

19. Pringsheim T, Davenport WJ, Dodick D. Acute treatment and prevention of menstrually related migraine headache: evidence-based review. Neurology 2008; 70(17): 1555-63.

20. D'Alessandro R, Gamberini G, Lozito A, Sacquegna T. Menstrual migraine: intermittent prophylaxis with a timed-release pharmacological formulation of dihydroergotamine. Cephalalgia 1983; 3 (Suppl 1) $156-8$.

21. Silberstein SD, Holland S, Freitag F, et al. Evidencebased guideline update: pharmacologic treatment for episodic migraine prevention in adults: report of the Quality Standards Subcommittee of the American Academy of Neurology and the American Headache Society. Neurology 2012; 78(17): 1337-45.

22. Martin VT, Behbehani M. Ovarian hormones and migraine headache: understanding mechanisms and pathogenesis - part 2. Headache 2006; 46(3): 365-86.

23. Mauskop A, Altura BT, Altura BM. Serum ionized magnesium levels and serum ionized calcium/ ionized magnesium ratios in women with menstrual migraine. Headache 2002; 42(4) 242-8.

24. MacGregor EA. Migraine headache in perimenopausal and menopausal women. Curr Pain Headache Rep 2009; 13(5):399-403.

25. Hagemann G, Ugur T, Schleussner E, et al. Changes in brain size during the menstrual cycle. PloS One 2011; 6(2), e14655

26. Dahl A, Russell D, Rootwelt K, Nyberg-Hansen 
R, Kerty E. Cerebral vasoreactivity assessed with transcranial Doppler and regional cerebral blood flow measurements. Dose, serum concentration, and time course of the response to acetazolamide. Stroke 1995;26(12) 2302-6.

27. Bigal ME, Liberman JN, Lipton RB. Obesity and migraine: a population study. Neurology 2006; 66(4) 545-50.

28. Settakis G, Molnár C, Kerényi L, et al. Acetazolamide as a vasodilatory stimulus in cerebrovascular diseases and in conditions affecting the cerebral vasculature. Eur J Neurol 2003; 10(6) 609-20.

29. Sorteberg W, Lindegaard KF, Rootwelt K, et al. Effect of acetazolamide on cerebral artery blood velocity and regional cerebral blood flow in normal subjects. Acta Neurochirurg 1989; 97(3-4):139-45.

30. Huang SY, McCullough RE, McCullough RG, et al. Usual clinical dose of acetazolamide does not alter cerebral blood flow velocity. Respir Physiol 1988; 72(3): 315-26.

31. Hauge A, Nicolaysen G, Thoresen M. Acute effects of acetazolamide on cerebral blood flow in man. Acta Physiol Scand 1983; 117(2) 233-9.

32. Ridderstråle $\mathrm{Y}$, Hanson $\mathrm{M}$. Histochemical study of the distribution of carbonic anhydrase in the cat brain. Acta Physiol Scand 1985; 124(4) 557-64.

33. Gans MS. Idiopathic intracranial hypertension (IIH): Treatment and management. Medscape 2019. https:// emedicine.medscape.com/article/1214410-treatment. Accessed: 02 January 2019

34. Kisabay Ak A, Tata G, Gokcay F, Celebisoy N. What is the optimal dose of acetazolamide in the treatment of idiopathic intracranial hypertension. Neurol Asia 2020; 25(1): 47-51. 